\title{
P50 The Administration of Losartan/Amlodipine in Fixed Combination Versus Losartan Improves the Hemodynamic and Arterial Stiffness Parameters in Patients with Systemic Hypertension Grade 1 and 2
}

Mayra Jimenez*, Fernando Grover, Marycruz Barocio, Ernesto Cardona, Patricia Quezada, Jhonatan Trujillo, David Cardona, Carlos Ramos

Department of Physiology, Arterial Stiffness Laboratory, Experimental Therapeutic and Clinic Institute, Health Sciences University Center, University of Guadalajara, Guadalajara, Mexico

\section{ABSTRACT}

Purpose/Background/Objectives: Hypertension (HAS) represents 9.4 million deaths from all the cases of cardiovascular disease worldwide [1]. The pulse wave velocity (PWV) and some hemodynamic parameters have been associated with this outcome [2,3]. Losartan, as well as amlodipine, have shown benefits on hemodynamic parameters [4,5] however, it is unknown if losartan/amlodipine combination is better than losartan as a monotherapy. We evaluated losartan/amlodipine effect in a fixed combination versus losartan on hemodynamic and arterial stiffness parameters in patients with systemic arterial hypertension.

Design and Methods: We conducted a randomized, double-blind study in 28 hypertensive patients according to AHA criteria 2017 [6]. 14 patients received losartan $100 \mathrm{mg}$ per day and 14 losartan/amlodipine 100/5 mg per day, for 8 weeks. Hemodynamic parameters and arterial stiffness measurement were performed with a Mobil-O-Graph ${ }^{\oplus}$ [7].

Results: The combination of losartan/amlodipine improved hemodynamic and arterial stiffness parameters compared with losartan, reducing peripheral vascular resistance (RVP) ( $0.10 \pm 0.08$ vs $0.05 \pm 0.08)$, PWV $(0.52 \pm 0.45$ vs $0.33 \pm 0.359)$, daytime PWV (7.24 \pm 0.90 vs $7.61 \pm 1.03)$, nocturnal PWV (6.86 \pm 0.96 vs $7.27 \pm 1.17)$ and diastolic blood pressure (DBP) (11.21 \pm 6.15 vs $5.92 \pm 7.65) . d$ )

Conclusion: We did not find differences between single or combined medication in terms of BP reduction. However, arterial stiffness parameters were better in the combined therapy.

\section{REFERENCES}

[1] Dasgupta K, Quinn RR, Zarnke KB, Rabi DM, Ravani P, Daskalopoulou SS, et al. The 2014 Canadian Hypertension Education Program recommendations for blood pressure measurement, diagnosis, assessment of risk, prevention, and treatment of hypertension. Can J Cardiol 2014;30:485-501.

[2] Parikh JD, Hollingsworth KG, Kunadian V, Blamire A, MacGowan GA. Measurement of pulse wave velocity in normal ageing: comparison of Vicorder and magnetic resonance phase contrast imaging. BMC Cardiovasc Disord 2016;16:50.

[3] Aoka Y, Hagiwara N, Kasanuki H. Heterogeneity of hemodynamic parameters in untreated primary hypertension, and individualization of antihypertensive therapy based on noninvasive hemodynamic measurements. Clin Exp Hypertens 2013;35:61-6.

[4] Raman VK, Tsioufis C, Doumas M, Papademetriou V. Renal denervation therapy for drug-resistant hypertension: does it still work? Curr Treat Options Cardiovasc Med 2017;19:39.

[5] Kurata M, Okura T, Watanabe S, Irita J, Enomoto D, Johtoku M, et al. Effects of amlodipine and candesartan on arterial stiffness estimated by cardio-ankle vascular index in patients with essential hypertension: a 24-week study. Curr Ther Res Clin Exp 2008;69:412-22.

[6] Whelton PK, Carey RM, Aronow WS, Casey DE, Collins KJ, Dennison Himmelfarb C, et al. 2017 ACC/AHA/AAPA/ABC/ ACPM/AGS/APhA/ASH/ASPC/NMA/PCNA Guideline for the Prevention, Detection, Evaluation, and Management of High Blood Pressure in Adults: A Report of the American College of Cardiology/American Heart Association Task Force on Clinical Practice Guidelines. Journal of the American College of Cardiology. 2017.

[7] Mobil-O-Graph ${ }^{\circledR}$. I.E.M. Industrielle Entwicklung Medizintechnik GmbH, Germany.

(c) 2019 Association for Research into Arterial Structure and Physiology. Publishing services by Atlantis Press International B.V. This is an open access article distributed under the CC BY-NC 4.0 license (http://creativecommons.org/licenses/by-nc/4.0/). 